\title{
Factors of Food Premises Not Attaining "A" Grading in Sabah, Malaysia Borneo
}

\author{
Narinderjeet Kaur ${ }^{1}$, Wafaak Esa ${ }^{2}$, Yanti Zahlan ${ }^{3}$, Jiloris F Dony ${ }^{2,4}$, Syed Sharizman Syed Abdul \\ Rahim $^{1, *}$, Mohammad Saffree Jeffree ${ }^{1}$, Khamisah Awang Lukman ${ }^{1}$, Mohd Faizal Madrim ${ }^{1}$, \\ Zulkhairul Naim Sidek Ahmad ${ }^{1}$ \\ ${ }^{1}$ Community and Family Medicine Department, Faculty of Medicine and Health Sciences, Universiti Malaysia Sabah, \\ 88400 Kota Kinabalu, Sabah, Malaysia \\ ${ }^{2}$ Kota Kinabalu Area Health Office, 88300 Kota Kinabalu, Sabah, Malaysia \\ ${ }^{3}$ Town Hall Kota Kinabalu, 88300 Kota Kinabalu, Sabah, Malaysia \\ ${ }^{4}$ Public Health Lab, Kota Kinabalu, 88300 Kota Kinabalu, Sabah, Malaysia
}

Received July 29, 2021; Revised September 1, 2021; Accepted October 17, 2021

\section{Cite This Paper in the following Citation Styles}

(a): [1] Narinderjeet Kaur, Wafaak Esa, Yanti Zahlan, Jiloris F Dony, Syed Sharizman Syed Abdul Rahim, Mohammad Saffree Jeffree, Khamisah Awang Lukman, Mohd Faizal Madrim, Zulkhairul Naim Sidek Ahmad , "Factors of Food Premises Not Attaining "A" Grading in Sabah, Malaysia Borneo," Universal Journal of Public Health, Vol. 9, No. 5, pp. 339 - 343, 2021. DOI: 10.13189/ujph.2021.090517.

(b): Narinderjeet Kaur, Wafaak Esa, Yanti Zahlan, Jiloris F Dony, Syed Sharizman Syed Abdul Rahim, Mohammad Saffree Jeffree, Khamisah Awang Lukman, Mohd Faizal Madrim, Zulkhairul Naim Sidek Ahmad (2021). Factors of Food Premises Not Attaining "A" Grading in Sabah, Malaysia Borneo. Universal Journal of Public Health, 9(5), 339 343. DOI: 10.13189/ujph.2021.090517.

Copyright@2021 by authors, all rights reserved. Authors agree that this article remains permanently open access under the terms of the Creative Commons Attribution License 4.0 International License

\begin{abstract}
Introduction: Up to $70 \%$ of the food-water related illness is related to food services hygiene and safety standard. An important and crucial enforcement operation conducted by this division is the inspection of premises and food sampling. This is of paramount importance as food premise grading is directly related to consumers' health and safety which is in line with the third United Nations Sustainable Developmental Goal of good health and wellbeing. Aim: This study aims to identify the components and factors that are commonly related with food premises that do not obtain an "A" grading. Methodology: A cross-sectional study was conducted in 2017 among 315 food premises in Kota Kinabalu, Sabah that were under the jurisdiction of The Kota Kinabalu City Hall. Data from the food premise inspection forms were reviewed and analysed via multivariate analysis. Results: Premises that were non-compliant with health checks on all food handlers (OR 36.72, 95\% CI 10.00-135.44), poor condition of the toilets (OR 6.96, 95\% CL 2.35-20.63), ineffective fly control (OR 10.35, 95\% CI 1.91-56.02), no availability of garbage cans (OR 3.01, 95\% CI 1.01-9.01) and no separate storage for food items and chemical (OR 3.11, 95\% 1.06-9.07) were significantly associated with
\end{abstract}

not obtaining "A" grading. Conclusion: More focus and attention need to be paid to these factors not only for premises to attain " $\mathrm{A}$ " grading but also to improve the safety and hygiene of food that is consumed by the public.

Keywords Food Hygiene, Food Premise, Food Safety, Grading

\section{Introduction}

Foodborne diseases are a real threat to the public as well as the food industry. Globally, it affects almost $30 \%$ of the population in developed countries [1]. The main bulk of foodborne disease is reported in the subregions of Africa, followed by Southeast Asia and the Eastern Mediterranean regions [2]. In Malaysia and particularly Sabah, the incidence of food borne disease have been fluctuating [3] as the number of cases reported are an underestimate as not all the cases present to the health facilities [1]. From 2011 to 2014, 1997 cases of foodborne diseases were reported in Sabah. From this number, majority (89.4\%) was from food 
poisoning cases. However, foodborne diseases is well known to be under reported [4]. Food premises have been associated with food borne disease such as salmonella infections [5], bacillus cereus infections as well as staphylococcal food intoxication [6]. Up to $70 \%$ of the food-water related illness is related to food services [7].

In Malaysia, The Food Safety and Quality Division, Ministry of Health was established to ensure that food processing and delivering activities are managed according to the required hygiene and safety standard. An important and crucial enforcement operation conducted by this division is the inspection of premises and food sampling. This is of paramount importance as food premise grading is directly related towards consumers' health and safety [8] which is in line with the third United Nations Sustainable Developmental Goal of good health and wellbeing.

This study aims to identify the components that are commonly non-compliance with among the food premises and to identify its association with not obtaining an 'A' grading premise. This information from this study will be vital as it can help improve the safety and quality of food premises thus translating into healthier populations. Components that are commonly neglected by food handles and premises can be highlighted and used in quality improvements and disseminated to the stakeholders, mainly food premise owners.

\section{Methodology}

A cross sectional study was conducted from January 2017 to April 2017 among the food premises in Kota Kinabalu, Sabah that were under the jurisdiction of The Kota Kinabalu City Hall. All food premises are rated either Grade A (85-100\%), B (60-84\%), C (< 60\%). Food premises are widely divided into two categories, category A and category B premises. Category A is made up by premise inspections are not under the jurisdiction of the City Hall for example school canteen, cafeteria in education institutions, caterer, kitchen, and canteen in health facilities. The inspection was conducted by the Food and Safety Quality unit of the district health office. Premises of category B are restaurant, fast food restaurant, cafeteria, food court and food kiosk and are inspected by the authorities from The Environmental Health Division of Kota Kinabalu City Hall.

The food premise inspection forms consist of seven components: food preparation area, food serving area, food handler, water supply system, sanitation system, structure and maintenance of premises and others. Premises that do not comply to the safety and hygienic standards are to be closed under the Food Act 1983. This Act protects consumers from food-related dangers and frauds, as well as to encourage and promote the safe preparation, handling, distribution, sale, and consumption of high-quality food [9].
All premises that were inspected during that period were included in this study. Premises with duplicate or incomplete inspection forms were excluded. The sample size was calculated using the Cochran formula and the required sample size was 354 accounting for $30 \%$ of the incomplete data using the prevalence of $23.2 \%$ of noncompliance to hand hygiene [10]. Data from the food premise inspection forms were reviewed and analysed using SPSS. Descriptive and multiple logistic regression was used to achieve the aim of this study.

For ethical reasons, the confidentiality of the food premises was protected, no name or identifiable information was exposed. Data collected was stored into a password protected database that is only accessible by the researcher. IBM SPSS software was used for the data analysis of this study. For descriptive statistics, all data was tabulated, and multiple logistic regression was used to analysis the data at the multivariate level.

During the dissemination of information based on the results of this study, no name of premise will be mentioned. This study was registered with the National Medical Research Register, Ministry of Health Malaysia (Research ID 38562) and has obtained approval for publication.

\section{Result}

A total of 315 food premises were inspected with the mean score obtained to be 80.75 . The minimum score was 57 and maximum score was 98 . Out of the 315 , majority food premises received Grade B (67\%) (Figure 1). Table 1 descriptively shows the compliance components in the food premises inspection such as food preparation area, food serving area, food handler, water supply system, sanitation system as well as structure and maintenance. Multiple logistic regression was conducted between non-compliance factors and Non- "A" grading food premises (Table 2).

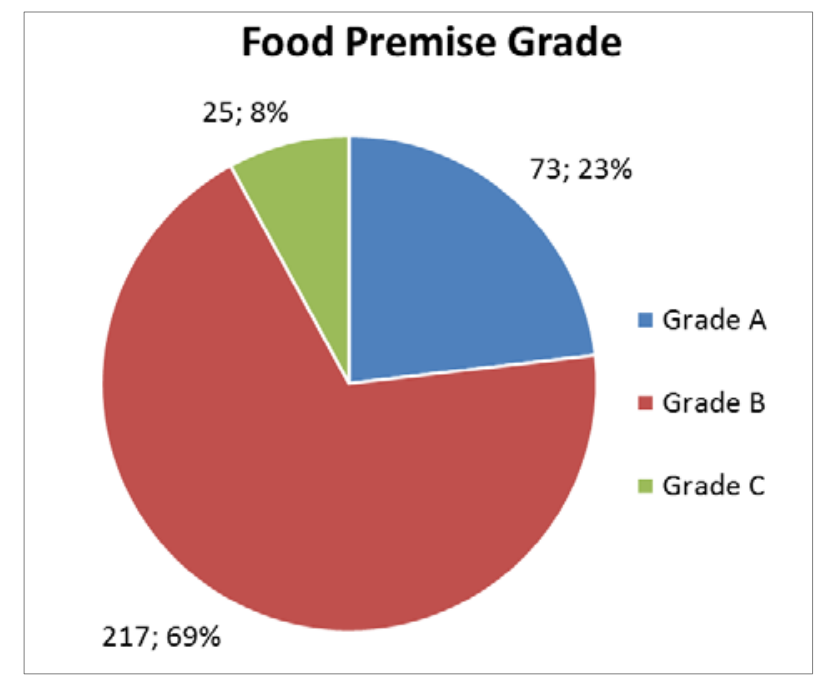

Figure 1. Grades attained from food premises inspection in Kota Kinabalu (n= 315) 
Premises that were non-compliant to health checks on all food handlers (OR 36.72, 95\% CI 10.00-135.44), poor condition of the toilets (OR 6.96, 95\% CI 2.35-20.63), ineffective fly control (OR 10.35, 95\% CI 1.91-56.02), no availability of garbage cans (OR 3.01, 95\% CI 1.01-9.01) and no separate storage for food items and chemical (OR 3.11, 95\% 1.06-9.07) were significantly associated with not obtaining " $\mathrm{A}$ " grading.

Table 1. Compliance to the components in the food premises inspection in Kota Kinabalu

\begin{tabular}{|c|c|c|}
\hline Components & Not compliant (\%) & Compliant (\%) \\
\hline \multicolumn{3}{|l|}{ Food Preparation Area } \\
\hline Temperature regulation for food preparation and storage & $10(3.2)$ & $305(96.8)$ \\
\hline Hygiene of refrigerator & $215(68.3)$ & $100(31.7)$ \\
\hline Hygiene of cooking equipment and facilities & $99(31.4)$ & $216(68.6)$ \\
\hline Smoke and heat release systems & $8(2.5)$ & 307 (97.5) \\
\hline The space between the appliance and the wall / floor & $142(45.1)$ & $173(54.9)$ \\
\hline Rat control & $8(2.5)$ & $307(97.4)$ \\
\hline Fly control & $67(21.3)$ & $248(78.8)$ \\
\hline Cockroach control & $15(4.7)$ & $300(95.2)$ \\
\hline \multicolumn{3}{|l|}{ Food Serving Area } \\
\hline $\begin{array}{l}\text { Temperature control and place of display of food is according to the condition } \\
\text { and type of food }\end{array}$ & 55 (17.5) & $260(82.5)$ \\
\hline Culinary equipment used for food delivery & $106(33.0)$ & $209(66.3)$ \\
\hline Wiping cloth, pads and cutting tools & $97(30.8)$ & $218(69.2)$ \\
\hline Table, chairs and equipment & $54(17.1)$ & 261 (82.9) \\
\hline \multicolumn{3}{|l|}{ Food Handler } \\
\hline Health check on all food handlers & $178(56.5)$ & $137(43.5)$ \\
\hline Good level of personal hygiene & $240(76.2)$ & $75(23.8)$ \\
\hline No health problems related to food contamination & $7(2.2)$ & $308(97.8)$ \\
\hline \multicolumn{3}{|l|}{ Water Supply System } \\
\hline Safe source of water supply & $1(0.3)$ & $314(99.7)$ \\
\hline Use of water supply & $69(21.9)$ & $246(78.1)$ \\
\hline No pipe leakage on the premises & $10(3.2)$ & $305(96.8)$ \\
\hline \multicolumn{3}{|l|}{ Sanitation System } \\
\hline Condition of toilet facilities & $178(71.2)$ & $72(28.8)$ \\
\hline Sufficient facilities & $107(34.0)$ & $208(66.0)$ \\
\hline Hand washing facilities & $95(34.7)$ & $179(65.3)$ \\
\hline \multicolumn{3}{|l|}{ Structure and Maintenance } \\
\hline Floor, wall and ceiling condition & $280(88.9)$ & $35(11.1)$ \\
\hline Ventilation and lighting & $26(8.3)$ & $289(91.7)$ \\
\hline Ideal drainage system & $41(13.0)$ & $274(87.0)$ \\
\hline Perfect wastewater management system & $29(9.2)$ & $285(90.8)$ \\
\hline \multicolumn{3}{|l|}{ Others } \\
\hline Customer feedback & $6(1.9)$ & $309(98.1)$ \\
\hline Enough trash bin, covered, clean and packed & $197(62.7)$ & $117(37.3)$ \\
\hline Food and chemicals should be stored separately. Both must be labelled & $144(45.9)$ & $170(54.1)$ \\
\hline Good store preparation and management & $148(47.1)$ & $166(52.9)$ \\
\hline Good solid waste management practices (isolation at source) & $183(58.1)$ & $131(41.6)$ \\
\hline $\begin{array}{l}\text { The premises and equipment should be well maintained, and the cleaning } \\
\text { schedule should be monitored continuously }\end{array}$ & $108(34.3)$ & $207(65.7)$ \\
\hline Notice of hygiene notice, safety practices, health education and smoking ban & $163(51.7)$ & $152(48.3)$ \\
\hline Control and safety at food premises & $182(58.0)$ & $132(42.0)$ \\
\hline
\end{tabular}


Table 2. Multiple logistic regression between noncompliant factors and Non-A grading of food premises

\begin{tabular}{lccc}
\hline Non-compliance components & Adjusted odds ratio (95\%CI) & Wald statistics & p-value \\
\hline Health checks on all food handlers & $36.72(10.00-135.44$ & 29.28 & $<0.001$ \\
Condition of the toilets & $6.96(2.35-20.63)$ & 12.28 & $<0.001$ \\
Effective fly control & $10.35(1.91-56.02)$ & 7.35 & 0.007 \\
Availability of garbage cans & $3.01(1.01-9.01)$ & 3.9 & 0.048 \\
Separate storage for food items and chemical items & $3.11(1.06-9.07)$ & 4.29 & 0.038 \\
\hline
\end{tabular}

\section{Discussion}

Foodborne intoxications remain as one of the common and yet still a major public health concern as it is still occurring and can be either in small or large numbers in clusters [4]. From the results we can identify that there were a few subcomponents that were significantly associated with not getting an 'A' grading, which include those non-compliant with health checks on all food handlers, poor condition of the toilets, ineffective fly control, unavailable garbage cans and unavailable separate storage for food items and chemical.

The first is the noncompliance with the health checks on all food handlers. This involves the medical screening, typhoid immunization as well as health briefing. This was similar to the finding conducted previously by [11]-[14], which mentions that staff not having medical certificates were associated with poor food quality and safety practices because poor knowledge leads to poor practices [15],[16].

The next was the condition of toilets. Toilets that are not clean contribute to an unsafe and unhygienic environment. This involves having clean water supply and the availability of soap [10]. Noncompliance with effective pest control was another subcomponent that was significant. This can be understood that flies are mechanical vectors and can contaminate food. Fly control can be accomplished by removing fly breeding sites, avoiding interaction between flies and disease-causing organisms, shielding humans and utensils from fly interaction [17].

The next is the noncompliance towards the availability of garbage cans. This comes under the component of proper waste disposal and waste management. Improper waste management attracts pest that can contaminate and spread diseases [10]. Besides that, there is a need to improve public awareness on the need to have a proper waste collection service to ensure suitable waste disposal that will curb the spread of foodborne diseases [18].

The last significant factor was the noncompliance with separate storage for food items and chemical items. This is an important factor in ensuring a safe and clean environment of the food premise as it a very important factor [11]. Cross contamination of the chemicals to the food can occur, compromising the safety of the food.

Other internal factors that may play a role include staff turnover, language barrier and educational level. Positive impact from proper training can be enhanced by monitoring the role food handlers in decreasing the foodborne outbreaks incidence rate [19]. Besides food handlers' knowledge and practice, information on food safety needs to be provided for the consumers to improve self-awareness [20].

\section{Conclusions}

Interestingly, many of these subcomponents hindered a premise from obtaining an A grading are easily emendable. More focus needs to be on these subcomponents to ensure all food premises comply with the safety and hygiene standards of this grading system.

\section{Funding}

This study is not funded by any organization.

\section{Conflict of Interest}

This study has no conflict of interest.

\section{Acknowledgements}

The authors would like to thank the Director General of Health Malaysia for the permission to publish this paper. We also would like to thank the Town Hall Kota Kinabalu and Sabah State Health Department for their support and collaboration.

\section{REFERENCES}

[1] S. Wahida, L. Mohd Nizam, W. A. Wan Zawiah, T. C. Tuan Zainazor, and H. Zaiton, "A review on incidences of foodborne diseases and interventions for a better national food safety system in Malaysia,” Malaysian Appl. Biol., 2017. 
[2] A. H. Havelaar et al., "World Health Organization Global Estimates and Regional Comparisons of the Burden of Foodborne Disease in 2010,” PLoS Medicine. 2015.

[3] C. Y. New et al., "Microbiological food safety in Malaysia from the academician's perspective," Food Research. 2017.

[4] S. Sharizman, S. Azhar, S. Idrus, Z. Azhar, R. Hassan, and N. Safian, "Spatial Analysis of Food and Waterborne Diseases in Sabah, Malaysia,” Sains Malaysiana, vol. 49, no. 7, pp. 1627-1638, 2020.

[5] B. A. Karim et al., "A Large Common Source Outbreak of Salmonella typhimurium Linked to Kuala Terengganu Night Markets, Malaysia, 2014,” 2017.

[6] Y. Wakabayashi et al., "Staphylococcal food poisoning caused by Staphylococcus argenteus harboring staphylococcal enterotoxin genes,” Int. J. Food Microbiol., 2018.

[7] K. Filion and D. A. Powell, "The use of restaurant inspection disclosure systems as a means of communicating food safety information,” J. Foodserv., 2009.

[8] J. E. Lee, B. A. Almanza, D. C. Nelson, and R. F. Ghiselli, "Using health inspection scores to assess risk in food services,” J. Environ. Health, 2009.

[9] A. Philipp, “Food Safety in Malaysia,” Japan Med Assoc J, 2015.

[10] S. S. Ntomola, "Determination of Hygienic Practice and Status of Food Handlers in Catering Premises: A Case Study of IlalaMunicipal Council,” 2014.

[11] N. A. Abdul-Mutalib, M. F. Abdul-Rashid, S. Mustafa, S. Amin-Nordin, R. A. Hamat, and M. Osman, "Knowledge, attitude and practices regarding food hygiene and sanitation of food handlers in Kuala Pilah, Malaysia," Food Control, 2012.
[12] O. K. Muinde and E. Kuria, "Hygienic and Sanitary Practices of Vendors of Street Foods in Nairobi Kenya," African J. Food Agric. Nutr. Dev., 2005.

[13] S. O. Nee and N. A. Sani, "Assessment of Knowledge, Attitudes and Practices (KAP) Among food handlers at residential colleges and canteen regarding food safety," Sains Malaysiana, 2011.

[14] S. K. Sagoo, C. L. Little, L. Ward, I. A. Gillespie, and R. T. Mitchell, "Microbiological study of ready-to-eat salad vegetables from retail establishments uncovers a national outbreak of salmonellosis,” J. Food Prot., 2003.

[15] D. L. T. Ng, M. A. Harris, T. H. Oiamo, and I. Young, "Spatial distribution and characteristics of restaurant inspection results in Toronto, Ontario, 2017-2018,” Food Prot. Trends, 2020.

[16] Abu Arrah Abdelhakeem, Bhatti Feyza, Al-Akash Hekmat, "Food Safety Knowledge among Food Handlers in Hospitals of Jordan," Food Science and Technology, Vol. 9, No. 2, pp. 17 - 30, 2021. DOI: 10.13189/fst.2021.090201.

[17] J. K. Das, Y. B. Hadi, R. A. Salam, M. Hoda, Z. S. Lassi, and Z. A. Bhutta, "Fly control to prevent diarrhoea in children," Cochrane Database of Systematic Reviews, vol. 2018, no. 12. John Wiley and Sons Ltd, 17-Dec-2018.

[18] T. R. Jerumeh, J. I. Igbinadolor, and T. O. Akinbinu, "Public health implications of solid waste management in Akure, Nigeria,” GeoJournal, pp. 1-11, Sep. 2020.

[19] W. Salleh, M.N. Lani, W. Z. W. Abdullah, T. Z. T. Chilek, and Z. Hassan. "A Review on Incidences of Foodborne Diseases and Interventions For A Better National Food Safety System In Malaysia, ” Malays. Appl. Biol. 2017.

[20] J. M. Soon. "Consumers' Awareness and Trust Toward Food Safety News on Social Media in Malaysia.” J Food Prot. 2020. 